\title{
Identification of Novel Genetic Susceptibility Loci in African American Lupus Patients in a Candidate Gene Association Study
}

\author{
Elena Sánchez, ${ }^{1}$ Mary E. Comeau, ${ }^{2}$ Barry I. Freedman, ${ }^{3}$ Jennifer A. Kelly, ${ }^{1}$ \\ Kenneth M. Kaufman, ${ }^{4}$ Carl D. Langefeld, ${ }^{2}$ Elizabeth E. Brown, ${ }^{5}$ Graciela S. Alarcón, ${ }^{5}$ \\ Robert P. Kimberly, ${ }^{5}$ Jeffrey C. Edberg, ${ }^{5}$ Rosalind Ramsey-Goldman, ${ }^{6}$ Michelle Petri, ${ }^{7}$ \\ John D. Reveille, ${ }^{8}$ Luis M. Vilá, ${ }^{9}$ Joan T. Merrill, ${ }^{10}$ Betty P. Tsao, ${ }^{11}$ Diane L. Kamen, ${ }^{12}$ \\ Gary S. Gilkeson, ${ }^{12}$ Judith A. James, ${ }^{10}$ Timothy J. Vyse ${ }^{13}$ on behalf of the International \\ Consortium on the Genetics of Systemic Lupus Erythematosus, Patrick M. Gaffney, ${ }^{1}$ \\ Chaim O. Jacob, ${ }^{14}$ Timothy B. Niewold,${ }^{15}$ Bruce C. Richardson, ${ }^{16}$ John B. Harley, ${ }^{17}$ \\ Marta E. Alarcón-Riquelme, ${ }^{18}$ and Amr H. Sawalha ${ }^{4}$
}

Objective. Candidate gene and genome-wide association studies have identified several disease susceptibility loci in lupus patients. These studies have largely

Supported by the NIH (grants R03-AI-076729, P20-RR020143, P20-RR-015577, P30-AR-053483, R01-AR-042460, R37-AI024717, R01-AI-031584, N01-AR-62277, P50-AR-048940, P01-AI083194, RC1-AR-058554, U19-AI-082714, HHSN-266200500026C, P30-RR-031152，P01-AR-049084，R01-AR-043274, R01-AI-063274, K08-AI-083790, P30-DK-42086, L30-AI-071651, UL1-RR-024999, K24-AR-002138, P602-AR-30692, UL1-RR-025741, R01-DE-018209, R01-AR-043727, UL1-RR-025005, UL1-RR-029882, P60-AR-049459, and AR-043814), the Lupus Research Institute, the Arthritis National Research Foundation, the American College of Rheumatology Research and Education Foundation, the University of Oklahoma College of Medicine, the Kirkland Scholar Program, the Alliance for Lupus Research, the US Department of Veterans Affairs, and the US Department of Defense (grant PR094002).

${ }^{1}$ Elena Sánchez, PhD, Jennifer A. Kelly, MPH, Patrick M. Gaffney, MD: Oklahoma Medical Research Foundation, Oklahoma City; ${ }^{2}$ Mary E. Comeau, MA, Carl D. Langefeld, PhD: Wake Forest University Health Sciences, Winston-Salem, North Carolina; ${ }^{3}$ Barry I. Freedman, MD: Wake Forest University School of Medicine, Winston-Salem, North Carolina; ${ }^{4}$ Kenneth M. Kaufman, PhD, Amr H. Sawalha, MD: Oklahoma Medical Research Foundation, University of Oklahoma Health Sciences Center, and Oklahoma City VA Medical Center, Oklahoma City; ${ }^{5}$ Elizabeth E. Brown, PhD, MPH, Graciela S. Alarcón, MD, MPH, Robert P. Kimberly, MD, Jeffrey C. Edberg, $\mathrm{PhD}$ : University of Alabama at Birmingham; ${ }^{6}$ Rosalind RamseyGoldman, MD, DrPH: Northwestern University Feinberg School of Medicine, Chicago, Illinois; ${ }^{7}$ Michelle Petri, MD, MPH: Johns Hopkins University School of Medicine, Baltimore, Maryland; ${ }^{8}$ John D. Reveille, MD: University of Texas Health Science Center at Houston; ${ }^{9}$ Luis M. Vilá, MD: University of Puerto Rico School of Medicine, San Juan, Puerto Rico; ${ }^{10}$ Joan T. Merrill, MD, Judith A. James, MD, PhD: Oklahoma Medical Research Foundation and University of Oklahoma Health Sciences Center, Oklahoma City; ${ }^{11}$ Betty P. Tsao, PhD: University of California, Los Angeles; ${ }^{12}$ Diane L. Kamen, MD, MSCR, been performed in lupus patients who are Asian or of European ancestry. This study was undertaken to examine whether some of these same susceptibility loci increase lupus risk in African American individuals.

Methods. Single-nucleotide polymorphisms tagging 15 independent lupus susceptibility loci were genotyped in a set of 1,724 lupus patients and 2,024 healthy controls of African American descent. The loci examined included PTPN22, FCGR2A, TNFSF4, STAT4, CTLA4, $P D C D 1, P X K, B A N K 1, M S H 5$ (HLA region), CFB (HLA region), C8orf13-BLK region, $M B L 2, K I A A 1542, I T G A M$, and MECP2/IRAK1.

Results. We found the first evidence of genetic association between lupus in African American patients and 5 susceptibility loci (C8orf13-BLK, BANK1, TNFSF4, KIAA1542, and CTLA4; $P=8.0 \times 10^{-6}$,

Gary S. Gilkeson, MD: Medical University of South Carolina, Charleston; ${ }^{13}$ Timothy J. Vyse, MA, MBBS, MRCP, PhD: King's College London and Guy's Hospital, London, UK; ${ }^{14}$ Chaim O. Jacob, MD, PhD: University of Southern California, Los Angeles; ${ }^{15}$ Timothy B. Niewold, MD: University of Chicago, Chicago, Illinois; ${ }^{16}$ Bruce C. Richardson, MD, PhD: University of Michigan and Ann Arbor VA Medical Center, Ann Arbor; ${ }^{17} \mathrm{John}$ B. Harley, MD, PhD: Cincinnati Children's Hospital Medical Center and Cincinnati VA Medical Center, Cincinnati, Ohio; ${ }^{18}$ Marta E. Alarcón-Riquelme, MD, PhD: Oklahoma Medical Research Foundation, Oklahoma City, and PfizerUniversity of Granada-Junta de Andalucia, Granada, Spain. Address correspondence to Amr H. Sawalha, MD, Oklahoma Medical Research Foundation, 825 NE 13th Street, MS\#24, Oklahoma City, OK 73104. E-mail: amr-sawalha@omrf.ouhsc.edu. Submitted for publication February 14, 2011; accepted in revised form July 19, 2011. 
$P=1.9 \times 10^{-5}, P=5.7 \times 10^{-5}, P=0.00099$, and $P=0.0045$, respectively). Further, we confirmed the genetic association between lupus and 5 additional lupus susceptibility loci (ITGAM, MSH5, CFB, STAT4, and FCGR2A;P $=7.5 \times 10^{-11}, P=5.2 \times 10^{-8}$, $P=8.7 \times 10^{-7}, P=0.0058$, and $P=0.0070$, respectively), and provided evidence, for the first time, of genome-wide significance for the association between lupus in African American patients and ITGAM and MSH5 (HLA region).

Conclusion. These findings provide evidence of novel genetic susceptibility loci for lupus in African Americans and demonstrate that the majority of lupus susceptibility loci examined confer lupus risk across multiple ethnicities.

Systemic lupus erythematosus (SLE) is a systemic autoimmune disease characterized by autoantibody production, abnormalities of immune system function, and damage in several organs. Although the exact pathogenesis of SLE is unknown, there is strong evidence for contributions of both genetic risk factors and environmental events, which lead to a break in immunologic self tolerance (1). SLE is 9 times more common in women than in men (2), particularly during the childbearing years. There are also marked disparities in SLE incidence and prevalence worldwide; SLE prevalence varies among different ethnic and geographic populations (3). SLE is 4 times more common in people of African American ancestry than in those of European ancestry $(4,5)$. In addition, African Americans have a markedly increased risk of developing lupus nephritis relative to European Americans (5). The ethnic and genetic heterogeneity of SLE may contribute to the complexity of its clinical manifestation.

Recent genome-wide association studies (GWAS) and candidate gene studies have identified $>30$ SLE risk alleles that are common in both populations of European ancestry and populations of Asian ancestry $(6,7)$. These include genes encoding proteins important for adaptive immunity and the production of autoantibodies (HLA alleles, BLK, BANK1, and PTPN22) (8-10), proteins with roles in innate immunity and interferon (IFN) signaling (ITGAM, STAT4, and IRF5) (8,11-13), and genes involved in DNA methylation (MECP2) (14), among others.

In this study, we analyzed 3,462 African American patients with lupus and controls and 286 Gullah African American patients with lupus and controls for genetic association with polymorphisms within 15 confirmed lupus susceptibility loci $(8,9,11-22)$. We con- firmed that HLA, STAT4, FCGR2A, and ITGAM are associated with SLE and provided evidence of genomewide significance of the association of HLA and ITGAM in African American patients with lupus. Further, we described, for the first time, genetic associations between C8orf13-BLK, BANK1, TNFSF4, CTLA4, and KIAA1542 and lupus in African American patients.

\section{PATIENTS AND METHODS}

Patients and controls. Two independent SLE casecontrol cohorts were recruited through a multicenter collaboration within the US and assembled at the Oklahoma Medical Research Foundation. The study included a total of 3,462 African American samples (1,569 SLE patients and 1,893 healthy controls) and 286 Gullah African American samples (155 SLE patients and 131 healthy controls) (23). Gullah subjects have a considerably lower level of non-African genetic admixture when compared to other African American populations. All cases fulfilled the American College of Rheumatology criteria for the classification of SLE (24). Informed consent was obtained from all subjects. The study was approved by the institutional review boards at each of the participating institutions.

Genotyping. Genotyping was performed using the Illumina Custom Bead system on an iSCAN instrument as part of a large lupus candidate gene association study, in order to reduce the cost of genotyping and maximize the sample size. The following single-nucleotide polymorphisms (SNPs) within 15 confirmed susceptibility loci for SLE were used: rs2476601 (PTPN22), rs1801274 (FCGR2A), rs2205960 (TNFSF4), rs7574865 (STAT4), $\operatorname{rs} 231775$ (CTLA4), rs11568821 (PDCD1), rs6445975 (PXK), rs10516487 (BANK1), rs3131379 (MSH5 within the class III major histocompatibility complex [MHC] region), rs1270942 (CFB within class III MHC), rs13277113 (C8orf13-BLK region), rs1800450 (MBL2), rs4963128 (KIAA1542), rs1143679 (ITGAM), and rs17435 (MECP2/IRAK1) (8-22,25). IRF5, a known SLE susceptibility gene, was not examined in the present study because it was extensively studied in an African American cohort with lupus that included some of the samples included in this study (26). Similarly, the genetic association between IL21 and lupus in African American patients has recently been demonstrated (27). These SNPs were selected because they tag independent lupus susceptibility loci in lupus patients of European ancestry. In addition, 161 admixture informative markers were genotyped and evaluated in our samples. The admixture informative markers were selected to distinguish 4 continental ancestral populations: Africans, Europeans, American Indians, and East Asians (28-32).

Data analysis. Samples with a genotype success rate of $<90 \%$ were excluded from the analysis. A total of 19 African American samples and 1 Gullah sample were removed due to a low genotype success rate. The remaining samples were then evaluated for duplicates or related individuals, and one individual from each pair was removed if the proportion of alleles with shared identity by descent was $>0.4$ in African American samples or $>0.35$ in Gullah samples (resulting in the exclusion of 57 African American and 8 Gullah samples). Samples with 

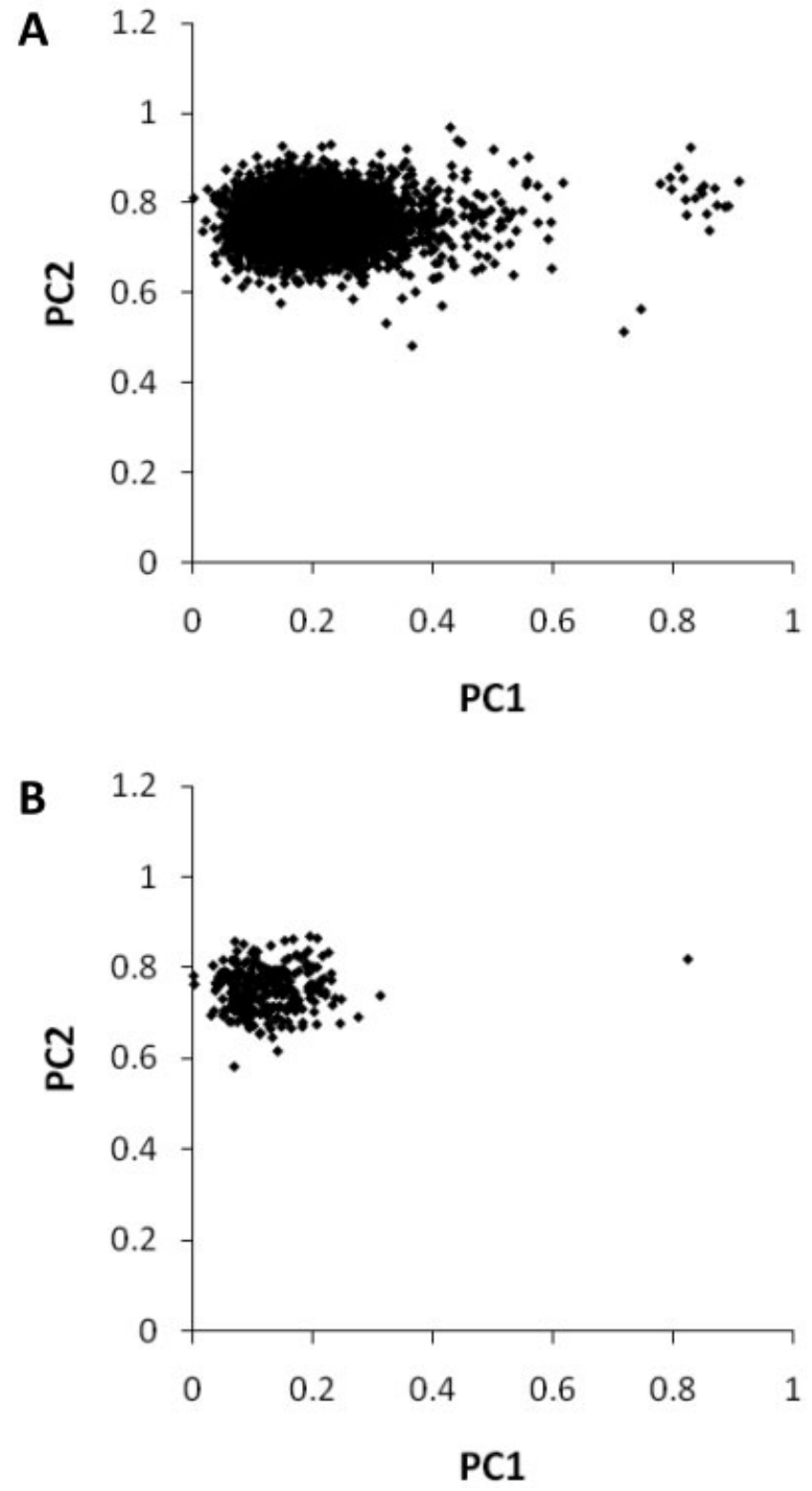

Figure 1. Scatter plots generated by the first 2 components of a principal components analysis of the African American samples (A) and the Gullah samples (B). The $\mathrm{x}$-axis shows principal component 1 (PC1), and the y-axis shows principal component 2 (PC2).

increased heterozygosity ( $>5 \mathrm{SD}$ from the mean) were then removed from the analysis. Samples were assessed for mismatches between reported sex and genetic data, and individuals with sex discrepancies were removed from the analysis. Finally, genetic outliers were removed from further analysis as determined by principal components analysis (Figure 1) and admixture estimates using AdmixMap software (33-35). A total of 30 genetic outliers were removed from the African American sample set, and 1 genetic outlier was removed from the Gullah sample set. After quality control, a total of 1,527 cases and 1,811 controls of African American descent and 152 cases and 123 controls of Gullah descent were included in subsequent analyses.

For each sample set analyzed, markers with a genotype success rate of $<90 \%$, Hardy-Weinberg equilibrium of $<0.001$, or minor allele frequency (MAF) of $<0.01$ were excluded from further analysis. All 15 markers were analyzed in the African American individuals, and 13 markers passed the inclusion threshold and were analyzed in the Gullah participants (2 SNPs were excluded due to MAF of <0.01).

To test for genetic association in SLE, we performed logistic regression, as implemented in Plink (36). Allele frequency differences between cases and controls were calculated with adjustment for the ancestry estimates provided by AdmixMap. Analysis was also performed separately with adjustment for the first 3 principal components. The results obtained by either method were very similar, and data adjusted for principal components are reported herein. Inflation factors $(\lambda)$ were calculated using "null" ancestry informative markers. Pooled odds ratios (ORs) were estimated using StatsDirect, version 2.4.6. The meta-analysis was conducted using standard methods based on the Cochran-Mantel-Haenszel test (37). The Breslow-Day test (38) was performed for all SNPs to assess the heterogeneity of the ORs in different populations.

\section{RESULTS}

Population structure analyses showed that the African ancestry and European ancestry was $81.3 \%$ and $15.7 \%$, respectively, among the African American samples, with an inflation factor $\lambda$ of 1.32 , and $90 \%$ and $7.2 \%$ among the Gullah samples, with an inflation factor $\lambda$ of 1.10. Therefore, all results presented herein were adjusted for principal components.

We genotyped 15 SNPs, tagging 15 independent susceptibility loci previously established in patients of European ancestry with SLE, in 2 independent cohorts of African descent. After excluding SNPs and individuals that did not pass our quality control standards, a total of 15 and 13 SNPs were analyzed in the African American and Gullah samples, respectively, in a total of 1,679 SLE patients and 1,934 controls. Two SNPs in the Gullah samples were excluded after MAF quality control (PDCD1 [rs11568821] and PTPN22 [rs2476601]).

Within the African American samples, we found evidence of significant genetic association between SLE and 10 loci after correction for the first 3 principal components. An association was observed for ITGAM $\left(P=1.9 \times 10^{-9}\right.$, OR 1.57$)$, MSH5 $\left(P=4.1 \times 10^{-8}, \mathrm{OR}\right.$ 1.65), $C F B\left(P=7.1 \times 10^{-7}\right.$, OR 1.63), C8orf13-BLK $\left(P=6.4 \times 10^{-6}\right.$, OR 1.36$), B A N K 1\left(P=5.9 \times 10^{-5}\right.$, OR 0.78), TNFSF4 $(P=0.00056$, OR 1.44), KIAA1542 $(P=0.0020$, OR 0.86), FCGR2A $(P=0.012$, OR 0.88), 
Table 1. Genetic associations between 15 lupus susceptibility loci and lupus in African Americans, adjusted for principal components*

\begin{tabular}{|c|c|c|c|c|c|c|c|c|}
\hline Gene & SNP & Chromosome & Position $\dagger$ & $\begin{array}{l}\text { Minor } \\
\text { allele }\end{array}$ & $\begin{array}{c}\text { MAF in cases } \\
\text { (no. of minor alleles/ } \\
\text { no. of major alleles) }\end{array}$ & $\begin{array}{l}\text { MAF in controls } \\
\text { (no. of minor alleles/ } \\
\text { no. of major alleles) }\end{array}$ & OR $(95 \% \mathrm{CI})$ & $P$ \\
\hline PTPN22 & rs2476601 & 1 & 114179091 & A & $0.018(56 / 2,996)$ & $0.014(50 / 3,568)$ & $1.31(0.90-1.92)$ & 0.16 \\
\hline$F C G R 2 A$ & rs1801274 & 1 & 159746369 & A & $0.429(1,298 / 1,726)$ & $0.460(1,645 / 1,931)$ & $0.88(0.80-0.97)$ & 0.012 \\
\hline TNFSF4 & rs 2205960 & 1 & 171458098 & A & $0.070(213 / 2,839)$ & $0.049(179 / 3,441)$ & $1.44(1.17-1.76)$ & 0.00056 \\
\hline STAT4 & rs 7574865 & 2 & 191672878 & A & $0.168(505 / 2,503)$ & $0.145(512 / 3,022)$ & $1.19(1.04-1.36)$ & 0.012 \\
\hline CTLA4 & rs231775 & 2 & 204440959 & G & $0.392(1,193 / 1,849)$ & $0.363(1,310 / 2,302)$ & $1.14(1.03-1.26)$ & 0.013 \\
\hline PDCD1 & rs11568821 & 2 & 242442585 & A & $0.026(78 / 2,956)$ & $0.020(69 / 3,441)$ & $1.31(0.94-1.81)$ & 0.11 \\
\hline$P X K$ & rs6445975 & 3 & 58345217 & A & $0.429(1,310 / 1,742)$ & $0.441(1,592 / 2,016)$ & $0.95(0.86-1.05)$ & 0.32 \\
\hline$B A N K 1$ & rs10516487 & 4 & 102970099 & A & $0.197(599 / 2,435)$ & $0.239(859 / 2,741)$ & $0.78(0.70-0.88)$ & $5.9 \times 10^{-5}$ \\
\hline MSH5 & rs 3131379 & 6 & 31829012 & A & $0.101(308 / 2,744)$ & $0.064(231 / 3,389)$ & $1.65(1.38-1.98)$ & $4.1 \times 10^{-8}$ \\
\hline$C F B$ & rs1270942 & 6 & 32026839 & G & $0.085(260 / 2,794)$ & $0.054(195 / 3,427)$ & $1.63(1.34-1.97)$ & $7.1 \times 10^{-7}$ \\
\hline C8orf13-BLK & rs13277113 & 8 & 11386595 & A & $0.172(520 / 2,506)$ & $0.131(467 / 3,111)$ & $1.36(1.19-1.55)$ & $6.4 \times 10^{-6}$ \\
\hline$M B L 2$ & rs1800450 & 10 & 54201241 & A & $0.032(98 / 2,952)$ & $0.029(104 / 3,514)$ & $1.12(0.84-1.48)$ & 0.45 \\
\hline KIAA1542 & rs4963128 & 11 & 579564 & A & $0.419(1,260 / 1,746)$ & $0.458(1,621 / 1,917)$ & $0.86(0.78-0.95)$ & 0.0020 \\
\hline ITGAM & rs1143679 & 16 & 31184312 & A & $0.153(467 / 2,583)$ & $0.104(375 / 3,233)$ & $1.57(1.36-1.82)$ & $1.9 \times 10^{-9}$ \\
\hline МECP 2 & rs17435 & 23 & 152965174 & A & $0.393(1,151 / 1,778)$ & $0.384(1,166 / 1,873)$ & $1.05(0.95-1.17)$ & 0.35 \\
\hline
\end{tabular}

* Odds ratios (ORs) represent differences in the minor allele frequency (MAF) between cases and controls in each locus. SNP $=$ single-nucleotide polymorphism; $95 \% \mathrm{CI}=95 \%$ confidence interval.

$\dagger$ Determined using Genome Build 36.3.

STAT4 $(P=0.012$, OR 1.19), and CTLA4 $(P=0.013$, OR 1.14) (Table 1).

Genetic association analysis of the Gullah samples revealed only 2 markers associated with SLE, TNFSF4 $(P=0.0015$, OR 4.99) and ITGAM $(P=$ 0.0080 , OR 1.97) (Table 2). Notably, these 2 markers were also associated with SLE in the African American participants.

Next, a meta-analysis was performed using the African American and Gullah data sets and the 13 SNPs that could be evaluated in both sample sets (Table 3).
The meta-analysis of these genetic markers in the African American and Gullah data sets using the Mantel-Haenszel test under a fixed-effects model revealed a significant association with SLE for FCGR2A $\left(P_{\text {meta }}=0.0070\right.$, OR $\left._{\text {meta }} 0.88\right)$, TNFSF4 $\left(P_{\text {meta }}=5.7 \times\right.$ $\left.10^{-5}, \mathrm{OR}_{\text {meta }} 1.51\right), \operatorname{STAT4}\left(P_{\mathrm{meta}}=0.0058, \mathrm{OR}_{\text {meta }}\right.$ $1.20), C T L A 4\left(_{\text {meta }}=0.0045, \mathrm{OR}_{\text {meta }} 1.15\right), B A N K 1$ $\left(P_{\text {meta }}=1.9 \times 10^{-5}, \mathrm{OR}_{\text {meta }} 0.78\right), M S H 5\left(P_{\text {meta }}=5.2 \times\right.$ $\left.10^{-8}, \mathrm{OR}_{\text {meta }} 1.63\right), C F B\left(P_{\text {meta }}=8.7 \times 10^{-7}, \mathrm{OR}_{\text {meta }}\right.$ $1.60), C 80 r f 13-B L K\left(P_{\text {meta }}=8.0 \times 10^{-6}\right.$, OR $\left._{\text {meta }} 1.34\right)$, KIAA1542 $\left(P_{\text {meta }}=0.00099, \mathrm{OR}_{\text {meta }} 0.86\right)$, and ITGAM

Table 2. Genetic associations between lupus susceptibility loci and lupus in Gullah subjects, adjusted for principal components*

\begin{tabular}{|c|c|c|c|c|c|c|c|c|}
\hline Gene & SNP & Chromosome & Position $\dagger$ & $\begin{array}{l}\text { Minor } \\
\text { allele }\end{array}$ & $\begin{array}{l}\quad \text { MAF in cases } \\
\text { (no. of minor alleles/ } \\
\text { no. of major alleles) }\end{array}$ & $\begin{array}{l}\text { MAF in controls } \\
\text { (no. of minor alleles/ } \\
\text { no. of major alleles) }\end{array}$ & OR $(95 \%$ CI $)$ & $P$ \\
\hline$F C G R 2 A$ & rs1801274 & 1 & 159746369 & A & $0.430(129 / 171)$ & $0.476(117 / 129)$ & $0.85(0.60-1.18)$ & 0.33 \\
\hline TNFSF4 & rs 2205960 & 1 & 171458098 & A & $0.092(28 / 276)$ & $0.020(5 / 241)$ & $4.99(1.85-13.43)$ & 0.0015 \\
\hline STAT4 & rs 7574865 & 2 & 191672878 & A & $0.150(44 / 250)$ & $0.107(26 / 218)$ & $1.39(0.85-2.29)$ & 0.19 \\
\hline CTLA4 & rs 231775 & 2 & 204440959 & G & $0.372(113 / 191)$ & $0.303(74 / 170)$ & $1.34(0.94-1.91)$ & 0.11 \\
\hline$P X K$ & rs6445975 & 3 & 58345217 & A & $0.398(121 / 183)$ & $0.390(96 / 150)$ & $1.03(0.73-1.44)$ & 0.87 \\
\hline BANK1 & rs10516487 & 4 & 102970099 & A & $0.211(64 / 240)$ & $0.262(64 / 180)$ & $0.74(0.50-1.10)$ & 0.14 \\
\hline MSH5 & rs3131379 & 6 & 31829012 & A & $0.053(16 / 288)$ & $0.045(11 / 235)$ & $1.19(0.55-2.60)$ & 0.66 \\
\hline$C F B$ & rs1270942 & 6 & 32026839 & G & $0.043(13 / 291)$ & $0.037(9 / 237)$ & $1.18(0.50-2.75)$ & 0.71 \\
\hline C8orf13-BLK & rs13277113 & 8 & 11386595 & A & $0.153(46 / 254)$ & $0.139(34 / 210)$ & $1.11(0.68-1.80)$ & 0.69 \\
\hline$M B L 2$ & rs 1800450 & 10 & 54201241 & A & $0.016(5 / 299)$ & $0.016(4 / 242)$ & $1.02(0.27-3.90)$ & 0.98 \\
\hline KIAA1542 & rs4963128 & 11 & 579564 & A & $0.389(115 / 181)$ & $0.438(105 / 135)$ & $0.82(0.58-1.15)$ & 0.25 \\
\hline ITGAM & rs1143679 & 16 & 31184312 & A & $0.191(58 / 246)$ & $0.110(27 / 219)$ & $1.97(1.19-3.26)$ & 0.0080 \\
\hline MECP 2 & rs17435 & 23 & 152965174 & A & $0.308(89 / 200)$ & $0.333(76 / 152)$ & $0.85(0.57-1.27)$ & 0.42 \\
\hline
\end{tabular}

* Two of the 15 single-nucleotide polymorphisms (SNPs) examined in the study were not included in this analysis due to low minor allele frequencies (MAFs) in the Gullah subjects. Odds ratios (ORs) represent differences in the MAF between cases and controls in each locus. $95 \% \mathrm{CI}=$ $95 \%$ confidence interval.

$\dagger$ Determined using Genome Build 36.3. 
Table 3. Meta-analysis of genetic associations in the African American samples and Gullah samples, adjusted for principal components*

\begin{tabular}{llcccc}
\hline \multicolumn{1}{c}{ Gene } & \multicolumn{1}{c}{ SNP } & OR $(95 \% \mathrm{CI})$ & $P_{\text {meta }}$ & $P_{\text {heterogeneity }}$ & $\begin{array}{c}\text { OR (95\% CI) in } \\
\text { European-derived } \\
\text { populations (ref.) }\end{array}$ \\
\hline FCGR2A & rs1801274 & $0.88(0.80-0.96)$ & 0.0070 & 0.81 & $0.86(0.77-0.92)(67)$ \\
TNFSF4 & rs2205960 & $1.51(1.24-1.86)$ & $5.7 \times 10^{-5}$ & 0.02 & $1.22(1.15-1.30)(67)$ \\
STAT4 & rs7574865 & $1.20(1.06-1.37)$ & 0.0058 & 0.54 & $1.57(1.49-1.69)(67)$ \\
CTLA4 & rs231775 & $1.15(1.04-1.26)$ & 0.0045 & 0.38 & $1.60(1.01-2.53)(68)$ \\
PXK† & rs6445975 & $0.96(0.87-1.05)$ & 0.36 & 0.67 & $0.80(0.74-0.86)(11)$ \\
BANK1 & rs10516487 & $0.78(0.76-0.87)$ & $1.9 \times 10^{-5}$ & 0.78 & $0.72(0.66-0.80)(9)$ \\
MSH5 & rs3131379 & $1.63(1.36-1.92)$ & $5.2 \times 10^{-8}$ & 0.42 & $2.36(2.11-2.64)(11)$ \\
CFB & rs1270942 & $1.60(1.33-1.94)$ & $8.7 \times 10^{-7}$ & 0.47 & $2.35(2.10-2.63)(11)$ \\
C8orf13-BLK & rs13277113 & $1.34(1.21-1.55)$ & $8.0 \times 10^{-6}$ & 0.42 & $1.39(1.28-1.51)(8)$ \\
MBL2 & rs1800450 & $1.11(0.85-1.47)$ & 0.45 & 0.90 & $1.33(1.08-1.65)(69)$ \\
KIAA1542 & rs4963128 & $0.86(0.77-0.94)$ & 0.00099 & 0.80 & $0.83(0.79-0.88)(67)$ \\
ITGAM & rs1143679 & $1.60(1.37-1.83)$ & $7.5 \times 10^{-11}$ & 0.40 & $1.78(1.56-2.03)(17)$ \\
MECP2 & rs17435 & $1.04(0.94-1.16)$ & 0.49 & 0.30 & $1.22(1.07-1.38)(70)$ \\
\hline
\end{tabular}

* Only the 13 single-nucleotide polymorphisms (SNPs) that passed quality control measures in both sample sets were included in this analysis. Odds ratios (ORs) represent differences in the minor allele frequency between cases and controls in each locus. 95\% CI $=95 \%$ confidence interval.

$\dagger$ The minor allele for the PXK polymorphism rs644975 is the $\mathrm{C}$ allele in populations of European ancestry and the A allele in African Americans.

$\left(P_{\text {meta }}=7.5 \times 10^{-11}, \mathrm{OR}_{\text {meta }} 1.60\right)($ Table 3$)$. Importantly, our data show that the risk alleles in the genetic associations we detected in lupus patients of African descent are the same as the risk alleles previously found in patients of European ancestry (Table 3).

\section{DISCUSSION}

The genetic heterogeneity between populations of different ethnicities has been suggested to be important in SLE risk (39), emphasizing the need for further studies in different populations. It has been consistently shown that patients of African descent have more severe lupus and a higher prevalence of lupus than those of European ancestry $(4,5)$. In an attempt to determine whether some of the lupus susceptibility genes identified in patients of European ancestry also confer disease susceptibility in populations of African descent, we studied 2 independent African American populations from the US and genotyped common variants that represent 15 of the most established genetic susceptibility loci for lupus.

We found evidence of association between SLE and 10 genetic variants in American patients of African descent. A meta-analysis of both of the African-derived populations that were examined revealed associations with genome-wide significance at 2 loci, ITGAM and MSH5 (in the HLA region).

The most significant effect was observed for a nonsynonymous SNP in the third exon of the ITGAM gene $\left(\mathrm{rs} 1143679\left[\mathrm{OR}_{\text {meta }} 1.60, P_{\text {meta }}=7.5 \times 10^{-11}\right)\right.$. This variant was previously shown to be associated with SLE in populations of African descent (17) and has been hypothesized to disturb the interaction between ITGAM and its ligands. Another genetic association that was established with genome-wide significance in the present study was within the HLA region in the MSH5 gene $\left(\mathrm{rs} 3131379\left[\mathrm{OR}_{\text {meta }} 1.63, P_{\text {meta }}=5.2 \times 10^{-8}\right)\right.$. It has previously been shown that the HLA region confers risk for lupus in African Americans (40-42), but this is the first study to establish this association with specific independent variants within this region and with genome-wide significance.

The next strongest associations were with 2 nonsynonymous polymorphisms (rs13277113 and rs10516487) located in the C8orf13-BLK locus and the $B A N K 1$ gene, respectively $\left(\mathrm{OR}_{\text {meta }} 1.34, P_{\text {meta }}=8.0 \times\right.$ $10^{-6}$ and $\mathrm{OR}_{\text {meta }} 0.78, P_{\text {meta }}=1.9 \times 10^{-5}$, respectively). C8orf13-BLK and BANK1 are involved in B cell receptor-mediated signaling and $B$ cell development $(43,44)$. Although no functional variant has been identified in C8orf13-BLK, the risk alleles of the rs13277113 SNP correlate with low levels of messenger RNA for $B L K$ and high levels of C8orf13, raising the possibility that either of these two effects could be related to SLE (8). In addition, it has been hypothesized that rs10516487 could potentially alter the affinity of BANK1 for inositol 1,4,5-trisphosphate receptor, altering B cell signaling in SLE patients (9). The TNFSF4 gene also 
showed a strong association with SLE in African American patients in the present study $\left(\mathrm{OR}_{\text {meta }} 1.51, P_{\text {meta }}=\right.$ $5.7 \times 10^{-5}$ ). TNFSF4 encodes the OX40 ligand, a costimulatory molecule involved in $\mathrm{T}$ cell activation. A similar association between TNFSF4 rs2205960 and SLE has been reported in Chinese patients (45).

Two other genes that were previously found to be associated with SLE in populations of African ancestry, STAT4 (rs7574865) and FCGR2A (rs1801274) $(21,46,47)$, were also found to be associated with SLE in the present study $\left(P_{\text {meta }}=0.0058\right.$ for STAT4 and $P_{\text {meta }}=0.0070$ for FCGR2A). The FCGR2A gene is located in a region that was previously found to be associated with SLE through linkage studies in African Americans (1q41) (47) and has been described as a risk factor for lupus nephritis in this population (21). FCGR2A is an important receptor that mediates phagocytic functions in different cells, and there is evidence that FCGR2A alleles confer distinct functional capacities to phagocytes, providing a mechanism for heritable susceptibility to immune complex-mediated disease $(48,49)$.

The association between STAT4 and SLE risk was initially reported in 2007 (13). This was subsequently confirmed by several GWAS in Europeans and Asians $(8,11,50,51)$ and in an African American cohort through high-density genotyping of STAT4 in different racial groups (46). STAT4 encodes a transcription factor that mediates the expression of genes in a number of key immunologic pathways and induces relevant cytokines, including type I IFNs, interleukin-12 (IL-12), and IL-23. STAT4 may also play a role in the differentiation of the potentially pathogenic Th17 T cell subset (52). Although no functional candidate polymorphism has yet been clearly established for STAT4, its roles in susceptibility to several autoimmune diseases and modulating immune functions suggest that it is an important gene in autoimmunity.

In previous studies, no association between CTLA4 and KIAA1542 genes and SLE in African Americans was found $(53,54)$. However, both genes were found to be associated with SLE in this study $\left(P_{\text {meta }}=\right.$ 0.0045 and $P_{\text {meta }}=0.00099$, respectively). The previous studies were underpowered to detect a significant association in these loci due to small sample sizes compared to the sample size in the present study. (The previous studies included 230 SLE patients and 276 controls [53] and 159 SLE patients and 115 controls [54].) Interestingly, the lupus-protective allele in rs4963128 (KIAA1542) has been associated with anti-Sm antibody in African American patients with lupus, and in the presence of anti-Sm, this same allele is associated with increased serum IFN $\alpha$ activity levels (55).

The rs6445975 SNP in the $P X K$ gene, rs2476601 in PTPN22, rs11568821 in PDCD1, and rs1800450 in the $M B L 2$ gene were not associated with SLE in the population examined in this study. The $P X K$ and $M B L 2$ variants have been shown to be associated with SLE in different European cohorts $(11,20)$; however, none of these associations has been replicated for other ethnic backgrounds (32,39,56-59). Previous studies of African American patients with SLE failed to show a significant genetic association between SLE and the PTPN22 and PDCD1 genes $(60,61)$. Ethnic differences in PTPN22 rs2476601 and PDCD1 rs11568821 allele frequencies have been described $(60,62)$. African Americans have much lower minor allele frequencies of rs2476601 (PTPN22) and rs11568821 (PDCD1) (2\% and 3\%, respectively) compared to individuals of European ancestry (8\% and $13 \%$, respectively) (62). Interestingly, neither of the minor alleles of these 2 SNPs is observed in populations of Asian descent (62-64). It is important to note that although we did not find an association between PTPTN22 or PDCD1 and SLE in African Americans, our study was underpowered to detect an association with an OR of 1.3 for PTPTN22 or PDCD1 ( $23 \%$ and $31 \%$, respectively), probably due to the lower MAF of these polymorphisms in African Americans compared to populations of European ancestry. Therefore, we cannot rule out a possible role of these 2 genes in African American patients with lupus.

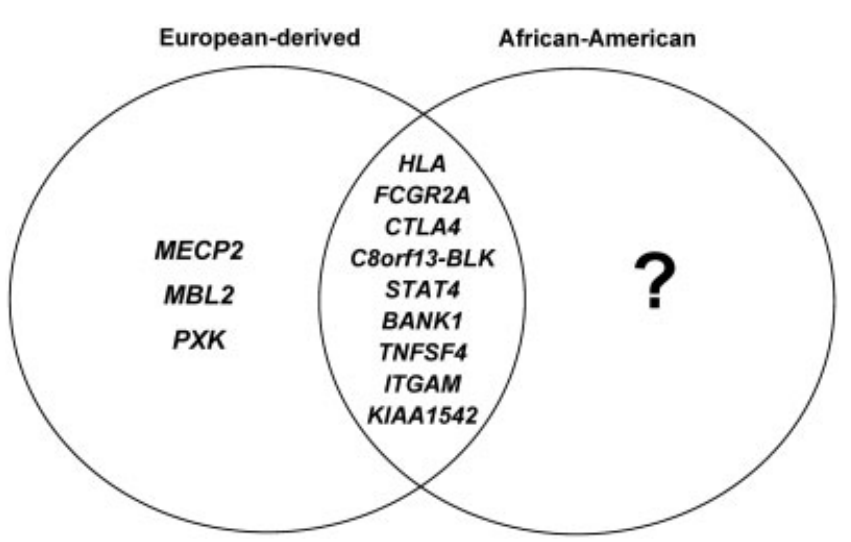

Figure 2. Lupus susceptibility loci that are unique to patients of European descent and those that are shared by patients of European descent and African American patients, determined based on the susceptibility loci included in this study and the results of the metaanalysis performed in the African American and Gullah sample sets. More genetic studies are needed to explain the higher prevalence and the more severe presentation of lupus in African Americans. 
In addition, the genetic association with rs 17435 within $M E C P 2$, which tags the MECP2/IRAK1 susceptibility locus that has been well established in Asian patients and patients of European ancestry with lupus $(14,65,66)$, was not replicated in the populations of African descent analyzed in the present study. However, fine-mapping and localization of the genetic effect in this locus in multiple ethnicities is under way (Kaufman KM, et al: unpublished observations).

The lack of genetic association between lupus in African American patients and some of the genetic susceptibility loci established in patients of European ancestry could be due to a different haplotype structure, given that causal variants for most of the genetic susceptibility loci have not been identified. Another possibility could be that some of the disease susceptibility loci operate in some, but not all, ethnicities. Figure 2 summarizes the unique and shared genetic susceptibility loci in SLE patients of European and African ancestry. Further studies of African American patients with lupus are needed to identify new and possibly unique SLE susceptibility loci in this population.

In summary, this is the first study to show a genetic association between lupus in African American patients and 5 loci (C8orf13-BLK, BANK1, CTLA4, KIAA1542, and TNFSF4). In addition, we established the genetic associations between SLE and the HLA region and between SLE and ITGAM with genome-wide significance in African Americans. We also confirmed the genetic association between SLE in African Americans and STAT4 and FCGR2A.

\section{AUTHOR CONTRIBUTIONS}

All authors were involved in drafting the article or revising it critically for important intellectual content, and all authors approved the final version to be published. Dr. Sawalha had full access to all of the data in the study and takes responsibility for the integrity of the data and the accuracy of the data analysis.

Study conception and design. Sánchez, Kaufman, Langefeld, Kimberly, Gaffney, Harley, Alarcón-Riquelme, Sawalha.

Acquisition of data. Sánchez, Freedman, Kelly, Kaufman, Brown, Alarcón, Kimberly, Edberg, Ramsey-Goldman, Petri, Reveille, Vilá, Merrill, Tsao, Kamen, Gilkeson, James, Vyse, Gaffney, Jacob, Niewold, Richardson, Harley, Sawalha.

Analysis and interpretation of data. Sánchez, Comeau, Kaufman, Langefeld, Tsao, Alarcón-Riquelme, Sawalha.

\section{REFERENCES}

1. Harley JB, Kelly JA, Kaufman KM. Unraveling the genetics of systemic lupus erythematosus. Springer Semin Immunopathol 2006;28:119-30.

2. Weckerle CE, Niewold TB. The unexplained female predominance of systemic lupus erythematosus: clues from genetic and cytokine studies. Clin Rev Allergy Immunol 2011;40:42-9.
3. Lau CS, Yin G, Mok MY. Ethnic and geographical differences in systemic lupus erythematosus: an overview. Lupus 2006;15:715-9.

4. Fessel WJ. Systemic lupus erythematosus in the community: incidence, prevalence, outcome, and first symptoms; the high prevalence in black women. Arch Intern Med 1974;134:1027-35.

5. Dooley MA, Hogan S, Jennette C, Falk R, for the Glomerular Disease Collaborative Network. Cyclophosphamide therapy for lupus nephritis: poor renal survival in black Americans. Kidney Int 1997;51:1188-95.

6. Delgado-Vega A, Sanchez E, Lofgren S, Castillejo-Lopez C, Alarcon-Riquelme ME. Recent findings on genetics of systemic autoimmune diseases. Curr Opin Immunol 2010;22:698-705.

7. Flesher DL, Sun X, Behrens TW, Graham RR, Criswell LA. Recent advances in the genetics of systemic lupus erythematosus. Expert Rev Clin Immunol 2010;6:461-79.

8. Hom G, Graham RR, Modrek B, Taylor KE, Ortmann W, Garnier $\mathrm{S}$, et al. Association of systemic lupus erythematosus with C8orf13BLK and ITGAM-ITGAX. N Engl J Med 2008;358:900-9.

9. Kozyrev SV, Abelson AK, Wojcik J, Zaghlool A, Linga Reddy MV, Sanchez E, et al. Functional variants in the B-cell gene BANK1 are associated with systemic lupus erythematosus. Nat Genet 2008;40:211-6.

10. Criswell LA, Pfeiffer KA, Lum RF, Gonzales B, Novitzke J, Kern $\mathrm{M}$, et al. Analysis of families in the Multiple Autoimmune Disease Genetics Consortium (MADGC) collection: the PTPN22 620W allele associates with multiple autoimmune phenotypes. Am J Hum Genet 2005;76:561-71.

11. Harley JB, Alarcon-Riquelme ME, Criswell LA, Jacob CO, Kimberly RP, Moser KL, et al. Genome-wide association scan in women with systemic lupus erythematosus identifies susceptibility variants in ITGAM, PXK, KIAA1542 and other loci. Nat Genet 2008;40:204-10.

12. Sigurdsson S, Nordmark G, Goring HH, Lindroos K, Wiman AC, Sturfelt G, et al. Polymorphisms in the tyrosine kinase 2 and interferon regulatory factor 5 genes are associated with systemic lupus erythematosus. Am J Hum Genet 2005;76:528-37.

13. Remmers EF, Plenge RM, Lee AT, Graham RR, Hom G, Behrens TW, et al. STAT4 and the risk of rheumatoid arthritis and systemic lupus erythematosus. N Engl J Med 2007;357:977-86.

14. Sawalha AH, Webb R, Han S, Kelly JA, Kaufman KM, Kimberly $\mathrm{RP}$, et al. Common variants within MECP2 confer risk of systemic lupus erythematosus. PLoS One 2008;3:e1727.

15. Graham RR, Kozyrev SV, Baechler EC, Reddy MV, Plenge RM, Bauer JW, et al. A common haplotype of interferon regulatory factor 5 (IRF5) regulates splicing and expression and is associated with increased risk of systemic lupus erythematosus. Nat Genet 2006;38:550-5.

16. Abelson AK, Delgado-Vega AM, Kozyrev SV, Sanchez E, Velazquez-Cruz R, Eriksson N, et al. STAT4 associates with systemic lupus erythematosus through two independent effects that correlate with gene expression and act additively with IRF5 to increase risk. Ann Rheum Dis 2009;68:1746-53.

17. Nath SK, Han S, Kim-Howard X, Kelly JA, Viswanathan P, Gilkeson GS, et al. A nonsynonymous functional variant in integrin- $\alpha \mathrm{M}$ (encoded by ITGAM) is associated with systemic lupus erythematosus. Nat Genet 2008;40:152-4.

18. Cunninghame Graham DS, Graham RR, Manku H, Wong AK, Whittaker JC, Gaffney PM, et al. Polymorphism at the TNF superfamily gene TNFSF4 confers susceptibility to systemic lupus erythematosus. Nat Genet 2008;40:83-9.

19. Torres B, Aguilar F, Franco E, Sanchez E, Sanchez-Roman J, Jimenez Alonso J, et al. Association of the CT60 marker of the CTLA4 gene with systemic lupus erythematosus. Arthritis Rheum 2004;50:2211-5.

20. Garred P, Madsen HO, Halberg P, Petersen J, Kronborg G, Svejgaard A, et al. Mannose-binding lectin polymorphisms and 
susceptibility to infection in systemic lupus erythematosus. Arthritis Rheum 1999;42:2145-52.

21. Salmon JE, Millard S, Schachter LA, Arnett FC, Ginzler EM, Gourley MF, et al. Fc $\gamma$ RIIA alleles are heritable risk factors for lupus nephritis in African Americans. J Clin Invest 1996;97: 1348-54.

22. Prokunina L, Castillejo-Lopez C, Oberg F, Gunnarsson I, Berg L, Magnusson V, et al. A regulatory polymorphism in PDCD1 is associated with susceptibility to systemic lupus erythematosus in humans. Nat Genet 2002;32:666-9.

23. Kamen DL, Barron M, Parker TM, Shaftman SR, Bruner GR, Aberle T, et al. Autoantibody prevalence and lupus characteristics in a unique African American population. Arthritis Rheum 2008; 58:1237-47.

24. Hochberg MC, for the Diagnostic and Therapeutic Criteria Committee of the American College of Rheumatology. Updating the American College of Rheumatology revised criteria for the classification of systemic lupus erythematosus [letter]. Arthritis Rheum 1997;40:1725.

25. Sawalha AH, Kaufman KM, Kelly JA, Adler AJ, Aberle T, Kilpatrick J, et al. Genetic association of interleukin-21 polymorphisms with systemic lupus erythematosus. Ann Rheum Dis 2008; 67:458-61.

26. Kelly JA, Kelley JM, Kaufman KM, Kilpatrick J, Bruner GR, Merrill JT, et al. Interferon regulatory factor-5 is genetically associated with systemic lupus erythematosus in African Americans. Genes Immun 2008;9:187-94.

27. Hughes T, Kim-Howard X, Kelly JA, Kaufman KM, Langefeld $\mathrm{CD}$, Ziegler J, et al. Fine-mapping and transethnic genotyping establish IL2/IL21 genetic association with lupus and localize this genetic effect to IL21. Arthritis Rheum 2011;63:1689-97.

28. Halder I, Shriver M, Thomas M, Fernandez JR, Frudakis T. A panel of ancestry informative markers for estimating individual biogeographical ancestry and admixture from four continents: utility and applications. Hum Mutat 2008;29:648-58.

29. Smith MW, Patterson N, Lautenberger JA, Truelove AL, McDonald GJ, Waliszewska A, et al. A high-density admixture map for disease gene discovery in African Americans. Am J Hum Genet 2004;74:1001-13.

30. Yang N, Li H, Criswell LA, Gregersen PK, Alarcon-Riquelme ME, Kittles R, et al. Examination of ancestry and ethnic affiliation using highly informative diallelic DNA markers: application to diverse and admixed populations and implications for clinical epidemiology and forensic medicine. Hum Genet 2005;118: 382-92.

31. Kosoy R, Nassir R, Tian C, White PA, Butler LM, Silva G, et al. Ancestry informative marker sets for determining continental origin and admixture proportions in common populations in America. Hum Mutat 2009;30:69-78.

32. Sanchez E, Webb RD, Rasmussen A, Kelly JA, Riba L, Kaufman KM, et al. Genetically determined Amerindian ancestry correlates with increased frequency of risk alleles for systemic lupus erythematosus. Arthritis Rheum 2010;62:3722-9.

33. McKeigue PM, Carpenter JR, Parra EJ, Shriver MD. Estimation of admixture and detection of linkage in admixed populations by a Bayesian approach: application to African-American populations. Ann Hum Genet 2000;64:171-86.

34. Hoggart CJ, Parra EJ, Shriver MD, Bonilla C, Kittles RA, Clayton DG, et al. Control of confounding of genetic associations in stratified populations. Am J Hum Genet 2003;72:1492-504.

35. Hoggart CJ, Shriver MD, Kittles RA, Clayton DG, McKeigue PM. Design and analysis of admixture mapping studies. Am J Hum Genet 2004;74:965-78.

36. Purcell S, Neale B, Todd-Brown K, Thomas L, Ferreira MA, Bender D, et al. PLINK: a tool set for whole-genome association and population-based linkage analyses. Am J Hum Genet 2007; 81:559-75.
37. Guedj M, Wojcik J, Della-Chiesa E, Nuel G, Forner K. A fast, unbiased and exact allelic test for case-control association studies. Hum Hered 2006;61:210-21.

38. Breslow NE, Day NE, Halvorsen KT, Prentice RL, Sabai C. Estimation of multiple relative risk functions in matched casecontrol studies. Am J Epidemiol 1978;108:299-307.

39. Yang W, Ng P, Zhao M, Hirankarn N, Lau CS, Mok CC, et al. Population differences in SLE susceptibility genes: STAT4 and BLK, but not PXK, are associated with systemic lupus erythematosus in Hong Kong Chinese. Genes Immun 2009;10:219-26.

40. Reveille JD, Schrohenloher RE, Acton RT, Barger BO. DNA analysis of HLA-DR and DQ genes in American blacks with systemic lupus erythematosus. Arthritis Rheum 1989;32:1243-51.

41. Sullivan KE, Wooten C, Schmeckpeper BJ, Goldman D, Petri MA A promoter polymorphism of tumor necrosis factor $\alpha$ associated with systemic lupus erythematosus in African-Americans. Arthritis Rheum 1997;40:2207-11.

42. Lee YH, Nath SK. Systemic lupus erythematosus susceptibility loci defined by genome scan meta-analysis. Hum Genet 2005;118: 434-43.

43. Yokoyama K, Su IH, Tezuka T, Yasuda T, Mikoshiba K, Tarakhovsky A, et al. BANK regulates BCR-induced calcium mobilization by promoting tyrosine phosphorylation of $\mathrm{IP}_{3}$ receptor. EMBO J 2002;21:83-92.

44. Saijo K, Schmedt C, Su IH, Karasuyama H, Lowell CA, Reth M, et al. Essential role of Src-family protein tyrosine kinases in NF- $\kappa \mathrm{B}$ activation during B cell development. Nat Immunol 2003;4:274-9.

45. Chang YK, Yang W, Zhao M, Mok CC, Chan TM, Wong RW, et al. Association of BANK1 and TNFSF4 with systemic lupus erythematosus in Hong Kong Chinese. Genes Immun 2009;10: $414-20$.

46. Namjou B, Sestak AL, Armstrong DL, Zidovetzki R, Kelly JA, Jacob N, et al. High-density genotyping of STAT4 reveals multiple haplotypic associations with systemic lupus erythematosus in different racial groups. Arthritis Rheum 2009;60:1085-95.

47. Moser KL, Neas BR, Salmon JE, Yu H, Gray-McGuire C, Asundi $\mathrm{N}$, et al. Genome scan of human systemic lupus erythematosus: evidence for linkage on chromosome 1q in African-American pedigrees. Proc Natl Acad Sci U S A 1998;95:14869-74.

48. Salmon JE, Edberg JC, Brogle NL, Kimberly RP. Allelic polymorphisms of human $\mathrm{Fc} \gamma$ receptor IIA and $\mathrm{Fc} \gamma$ receptor IIIB independent mechanisms for differences in human phagocyte function. J Clin Invest 1992;89:1274-81.

49. Salmon JE, Edberg JC, Kimberly RP. Fc $\gamma$ receptor III on human neutrophils: allelic variants have functionally distinct capacities. J Clin Invest 1990;85:1287-95.

50. Han JW, Zheng HF, Cui Y, Sun LD, Ye DQ, Hu Z, et al. Genome-wide association study in a Chinese Han population identifies nine new susceptibility loci for systemic lupus erythematosus. Nat Genet 2009;41:1234-7.

51. Yang W, Shen N, Ye DQ, Liu Q, Zhang Y, Qian XX, et al, Asian Lupus Genetics Consortium (ALGC). Genome-wide association study in Asian populations identifies variants in ETS1 and WDFY4 associated with systemic lupus erythematosus. PLoS Genet 2010;6:e1000841

52. Mathur AN, Chang HC, Zisoulis DG, Stritesky GL, Yu Q, O'Malley JT, et al. Stat3 and Stat4 direct development of IL-17secreting Th cells. J Immunol 2007;178:4901-7.

53. Parks CG, Hudson LL, Cooper GS, Dooley MA, Treadwell EL, St Clair EW, et al. CTLA-4 gene polymorphisms and systemic lupus erythematosus in a population-based study of whites and African-Americans in the southeastern United States. Lupus 2004:13:784-91.

54. Fu Q, Zhao J, Qian X, Wong JL, Kaufman KM, Yu CY, et al. Association of a functional IRF7 variant with systemic lupus erythematosus. Arthritis Rheum 2011;63:749-54.

55. Salloum R, Franek BS, Kariuki SN, Rhee L, Mikolaitis RA, Jolly 
$\mathrm{M}$, et al. Genetic variation at the IRF7/PHRF1 locus is associated with autoantibody profile and serum interferon- $\alpha$ activity in lupus patients. Arthritis Rheum 2010;62:553-61.

56. Kim EM, Bang SY, Kim I, Shin HD, Park BL, Lee HS, et al. Different genetic effect of PXK on systemic lupus erythematosus in the Korean population. Rheumatol Int 2011. E-pub ahead of print.

57. Tsai YC, Yao TC, Kuo ML, Cheng TT, Huang JL. Lack of association of mannose-binding lectin gene polymorphisms with development and clinical manifestations of systemic lupus erythematosus in Chinese children. Lupus 2009;18:372-6.

58. Li SG, Huang F, Liu XY, Deng XX, Xu M, Cong XZ, et al. The role of mannose binding lectin in the pathogenesis of systemic lupus erythematosus. Zhonghua Yi Xue Za Zhi 2006;86:463-7. In Chinese.

59. Monticielo OA, Chies JA, Mucenic T, Rucatti GG, Junior JM, da Silva GK, et al. Mannose-binding lectin gene polymorphisms in Brazilian patients with systemic lupus erythematosus. Lupus 2010; 19:280-7.

60. Lea W, Lee Y. The association between the PTPN22 C1858T polymorphism and systemic lupus erythematosus: a meta-analysis update. Lupus 2011;20:51-7.

61. Lee YH, Woo JH, Choi SJ, Ji JD, Song GG. Association of programmed cell death 1 polymorphisms and systemic lupus erythematosus: a meta-analysis. Lupus 2009;18:9-15.

62. Mori M, Yamada R, Kobayashi K, Kawaida R, Yamamoto K. Ethnic differences in allele frequency of autoimmune-diseaseassociated SNPs. J Hum Genet 2005;50:264-6.

63. Lee HS, Korman BD, Le JM, Kastner DL, Remmers EF, Gregersen PK, et al. Genetic risk factors for rheumatoid arthritis differ in Caucasian and Korean populations. Arthritis Rheum 2009;60:364-71.

64. Ban Y, Tozaki T, Taniyama M, Tomita M. The codon 620 single nucleotide polymorphism of the protein tyrosine phosphatase-22 gene does not contribute to autoimmune thyroid disease susceptibility in the Japanese. Thyroid 2005;15:1115-8.

65. Suarez-Gestal M, Calaza M, Endreffy E, Pullmann R, Ordi-Ros J, Sebastiani GD, et al. Replication of recently identified systemic lupus erythematosus genetic associations: a case-control study. Arthritis Res Ther 2009;11:R69.

66. Jacob CO, Zhu J, Armstrong DL, Yan M, Han J, Zhou XJ, et al. Identification of IRAK1 as a risk gene with critical role in the pathogenesis of systemic lupus erythematosus. Proc Natl Acad Sci U S A 2009;106:6256-61.

67. Gateva V, Sandling JK, Hom G, Taylor KE, Chung SA, Sun X, et al. A large-scale replication study identifies TNIP1, PRDM1, JAZF1, UHRF1BP1 and IL10 as risk loci for systemic lupus erythematosus. Nat Genet 2009;41:1228-33.

68. Pullmann R Jr, Lukac J, Skerenova M, Rovensky J, Hybenova J, Melus V, et al. Cytotoxic T lymphocyte antigen 4 (CTLA-4) dimorphism in patients with systemic lupus erythematosus. Clin Exp Rheumatol 1999;17:725-9.

69. Lee YH, Witte T, Momot T, Schmidt RE, Kaufman KM, Harley $\mathrm{JB}$, et al. The mannose-binding lectin gene polymorphisms and systemic lupus erythematosus: two case-control studies and a meta-analysis. Arthritis Rheum 2005;52:3966-74.

70. Webb R, Wren JD, Jeffries M, Kelly JA, Kaufman KM, Tang Y, et al. Variants within MECP2, a key transcription regulator, are associated with increased susceptibility to lupus and differentia gene expression in patients with systemic lupus erythematosus. Arthritis Rheum 2009;60:1076-84. 